\title{
Etriyesiz Dış Kiriş-Kolon Birleşim Bölgesi için Kesme Dayanımı Tahmini
}

\author{
Eren YAĞMUR*
}

\author{
Abdullah Gül Üniversitesi, Inşaat Mühendisliği Bölümü, Kayseri, Türkiye \\ (ORCID: 0000-0001-5938-0501)
}

\begin{abstract}
$\ddot{O} \mathbf{z}$
Çerçeve türü yapıların sismik yük altında sünek davranış sergilemesi kiriş-kolon birleşim bölgelerinin depremden kaynaklı olarak açığa çıkan reaksiyon kuvvetlerini sağlıklı bir şekilde aktarmasına bağlıdır. Ancak yüksek kesmeye maruz kalan birleşim bölgelerinde etriye sıklaştırması yapılırken çeşitli sorunlarla karşılaşılmakta ve bu sebeple de etriyeler gerektiği gibi yerleştirilememektedir. Sonuç olarak pek çok yapıda kiriş-kolon birleşim bölgesinde yetersiz etriye miktarı sebebi ile hasarlar meydana gelmektedir. Mevcut çalışmada, etriyesiz dış kirişkolon birleşim bölgelerinin kesme dayanımlarının belirlenmesi amacıyla yapılmış olan deney verileri derlenmiş ve bu verilere bağlı olarak birleşim bölgesinin kesme dayanımına etki eden temel parametreler belirlenmiştir. Bu parametreler: efektif birleşim bölgesi genişliği, beton silindir basınç dayanımı, eksenel kuvvet oranı ve kiriş efektif alanının kolon efektif alanına oranıdır. Söz konusu parametrelerden yola çıkılarak etriyesiz dış kiriş-kolon birleşim bölgelerinin kesme dayanımını hesaplamak amacıyla bir denklem önerilmiştir. Önerilen denklem literatürde yer alan ve aynı amaçla üretilmiş denklemlerin sonuçları ile karşılaştırılmıştır. Önerilen denklemin diğer denklem sonuçlarına kıyasla deney sonuçları ile daha uyumlu sonuçlar verdiği görülmüştür.
\end{abstract}

Anahtar kelimeler: Kiriş-Kolon, Birleşim Bölgesi, Deprem, Kesme Dayanımı, Etriye.

\section{Shear Strength Prediction for Exterior Beam-Column Joint}

\begin{abstract}
The ductile behavior of frame structures under seismic load is due to the healthy transfer of which reaction forces generated by the earthquake in the beam-column joints. However, in the joint areas which are exposed to high shear, various problems are encountered while concentrating the stirrups and therefore the stirrups cannot be placed properly. As a result, damages occur in many structures due to insufficient amount of stirrups in the beam-column joint areas. In the present study, the experimental data which was made in order to determine the shear strength of the external beam-column joint areas without stirrups were compiled and the basic parameters affecting the shear strength of the joint area were determined. These parameters are: the effective joint area width, the concrete cylinder compressive strength, the axial force ratio, and the ratio of the effective area of beam to the column effective area. Based on these parameters, an equation has been proposed in order to calculate the shear strength of the external beam-column joint areas without stirrup. The proposed equation has been compared with the results of the equations produced in the literature for the same purpose. It was found that the proposed equation gave results more consistent with the results of the experiments compared to the results of other equations.
\end{abstract}

Keywords: Beam-Column, Joint, Earthquake, Shear Strength, Stirrup.

\section{Giriş}

Deprem yükü altındaki bir yapının sünek davranış sergilemesi beklenmektedir, ancak çerçeve türü yapılarda elemanların tekil olarak gerekli şartları sağlaması bunun için yeterli olmamaktadır. Bu tür yapılarda, deprem yükünden kaynaklı olarak kiriş-kolon birleşim bölgelerinde yüksek oranda kesme kuvveti açığa çıkmakta ve söz konusu bölgeler önemli ölçüde zorlamalara maruz kalmaktadır. Birleşim bölgesinde oluşacak ciddi bir hasar yapının rijitliğinin aniden düşmesine sebep olmaktadır. Ülkemiz geçmişte pek çok yüksek şiddetli depreme maruz kalmıştır (Erzincan, 1992; Dinar, 1995; Adana, 1998;

*Sorumlu yazar: eren.yagmur@agu.edu.tr

Geliş Tarihi: 26.06.2019, Kabul Tarihi: 23.10.2019 
Kocaeli, 1999; Düzce, 1999; Bingöl, 2003; vd.) ve bu depremler sonrasinda hasar alan yapılar incelendiğinde kiriş-kolon birleşim bölgesi hasarlarının yaygın olarak ortaya çıktığı görülmüştür.

Bir kiriş-kolon birleşim bölgesinin çerçevedeki temel işlevi, kiriş uçlarında açığa çıkacak olan gerilmeleri kolona aktarmaktır. Kuvvetli kolon-zayıf kiriş uygulaması da bu aktarımın sağlanabilmesi için gerekli şartlardan birisidir. Bu uygulamanın temel amacı, yapının yatay yükler altında göreceği hasar miktarının düşük düzeylerde kalması için herhangi bir kolonun göçmeye maruz kalması tüm yapıyı doğrudan ilgilendireceğinden, kolonlardan önce kirişlerin deformasyona uğramasının istenmesidir [1]. Birleşim bölgesinde elemanlar arasında gerilme aktarımının sağlanabilmesi için söz konusu bölgelerde yüksek miktarda kesme donatısı kullanımı gerekmektedir. Ancak yönetmeliğin gereklerini bu tip bölgelerde yerine getirmek oldukça zordur. Kiriş-kolon birleşim bölgelerinin sismik aktivite sonrasındaki davranışlarının değerlendirilmesi sonucunda betonun sıkıştırılması sırasında kullanılan tekniklere bağlı olarak birleşim bölgesinde yer alan etriye düzeninin bozulduğu ve bu bölgelerde betonlama miktarının yetersiz şekilde yapıldığı sonuçlarına varılmıştır [2]. Bununla birlikte, deprem sonrası hasar alan yapılara bakıldığında, etriye yerleştirilmesinin zorluğundan dolayı bazı yapılarda kiriş-kolon birleşim bölgelerinde hiç etriye kullanılmamış olması ile dahi karşılaş1labilmektedir.

Tüm dünyada olduğu gibi ülkemizde de çerçeve türü yapı stoğu oldukça fazladır. Buna karşın kiriş-kolon birleşim bölgelerine gereken önemin verilmesi yakın bir geçmişe sahiptir. Pek çok ülkede 1970 öncesi yönetmeliklerde birleşim bölgelerinde donatı detayının göz ardı edilmiş olduğu bilinen bir gerçektir. Türkiye'de dügüm noktası kesme güvenliğine ilk olarak 1968 Deprem Yönetmeliğinde [3] yüzeysel olarak yer verilmiştir. 1975 Deprem Yönetmeliğinde [4] ise birleşim bölgesine özellikle değinilmiş ve konu şekillerle desteklenerek daha kapsamlı olarak açıklanmaya başlanmıştır. Ülkemizde son olarak yürürlüğe giren 2019 Deprem Yönetmeliğinde [5] ise kiriş-kolon birleşim bölgelerinin kesme dayanımı hesap esaslarına ve donatılandırma koşullarına ayrıntılı olarak yer verilmiştir. Ancak, Türkiye'de betonarme uygulamalar 1906'da Saint Antuan kilisesi ile başlamış ve günümüze kadar da hızla artarak devam etmiştir. Türkiye'de 1906-1968 yılları arasında inşa edilen pek çok betonarme yapı hala kullanım durumundadır.

Çalışma kapsamında, literatürde yer alan etriyesiz dış kiriş-kolon birleşim bölgesi deney verileri toplanmış, söz konusu elemanlara etki eden parametreler belirlenmiş, bu parametrelere bağlı olarak yeni bir kesme dayanımı hesap denklemi önerilmiştir. Önerilen denklem, farklı hasar durumları için, geçerliliği gösterilmiş mevcut denklem sonuçları ve deneysel çalışmaların sonuçları ile karşılaştırılmalı olarak sunulmuştur.

\section{Materyal ve Metot}

Çalışma kapsamında etriyesiz dış kiriş-kolon birleşim bölgelerinin kesme dayanımlarını hesaplamak amaciyla bir adet formül önerilmiştir. Bu sebeple literatürde yer alan 25 farklı çalışmadan 68 adet etriyesiz diş kiriş-kolon birleşim bölgesi deney verisi derlenmiş ve özellikleri Tablo 1'de verilmiştir. Kullanılan verilerin büyük çoğunluğu Park ve Mosalam [6]'ın çalışmalarında kullandıkları verilerle benzerlik göstermektedir. Önerilen formülden elde edilen sonuçların karşılaştırılması amacı ile literatürde yer alan ve aynı amaç için üretilmiş formüller kullanılmıştır.

\subsection{Deneysel Veri Tabanı}

Belli bir amaç için oluşturulan denklemlerin geçerliliğini göstermek için deneysel veri tabanlarının oluşturulması ve sonuçların karşılaştırılması önemlidir. Bu amaçla 25 farklı çalışmadan 68 adet etriyesiz dış kiriş-kolon birleşim bölgesi deney verisi toplanmıştır. Dikkate alınan eleman tipleri Şekil 1'de gösterildiği gibidir.

Numune özellikleri Tablo 1'de verilmiştir. Tabloda yer alan elemanlar, sismik yük etkisi altında denenmiştir ve elemanlarda döşeme yer almamaktadır. Tablo 1'de verilen parametreler silindir beton basınç dayanımı (18.0 $\left.\leq f_{c} \leq 104.0 \mathrm{MPa}\right)$, efektif birleşim bölgesi genişliği $\left(125.0 \leq b_{j} \leq 431.8\right.$ $\mathrm{mm})$, kolon yüksekliği (150 $\left.\leq h_{c} \leq 457.2 \mathrm{~mm}\right)$, kiriş yüksekliği $\left(200 \leq h_{b} \leq 762 \mathrm{~mm}\right)$, ve kolon eksenel yükünün $(P)$ beton basınç dayanımı ve kolonun kesit alanına $\left(A_{g}=b_{c} h_{c}\right)$ oranıdır $\left(0 \leq \frac{P}{f_{c} A_{g}} \leq\right.$ 0.86). Deneyler sonucunda görülen hasar durumları ise; 
(B) birleşim bölgesinde kiriş donatısında akma meydana gelmeden açığa çıkan kesme hasarı,

(BK) birleşim bölgesinde kiriş donatısında akma meydana geldikten sonra açığa çıkan kesme hasarı,

(KE) kirişte eğilme kırılması,

(CE) kolonda eğilme kırılması,

(KS) kiriş donatısındaki sıyrılmadan kaynaklı hasar durumu,

(H) kiriş boyuna donatısının bükülme şeklinden kaynaklı hasar durumudur.

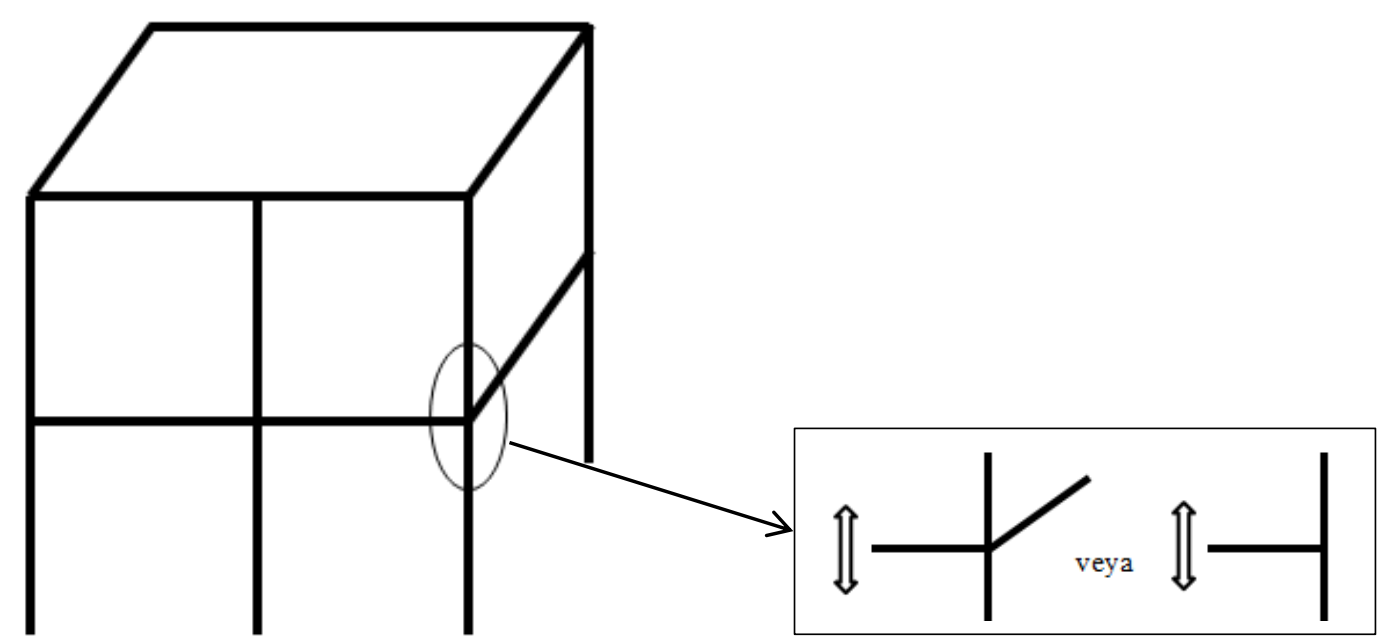

Şekil 1. Kiriş-kolon bağlantı şekilleri

Tablo 1. Etriyesiz dıș kiriş-kolon birleşim bölgesi veri tabanı

\begin{tabular}{ccccccccc}
\hline Referans & Numune & $\begin{array}{c}f_{c} \\
(M P a)\end{array}$ & $\begin{array}{c}b_{j} \\
(\mathrm{~mm})\end{array}$ & $\begin{array}{c}h_{c} \\
(\mathrm{~mm})\end{array}$ & $\begin{array}{c}h_{b} \\
(\mathrm{~mm})\end{array}$ & $\begin{array}{c}P \\
f_{c} A_{g}\end{array}$ & $\begin{array}{c}V \\
(\mathrm{kN})\end{array}$ & $\begin{array}{c}\text { Hasar } \\
\text { Tipi }\end{array}$ \\
\hline Hanson ve Conner [7] & $\mathrm{V}$ & 22.8 & 342.9 & 381.0 & 508.0 & 0.86 & 615.7 & $\mathrm{~B}$ \\
\hline \multirow{2}{*}{ Uzumeri [8] } & $\mathrm{SP1}$ & 30.8 & 342.9 & 381.0 & 508.0 & 0.41 & 626.8 & $\mathrm{BK}$ \\
& $\mathrm{SP} 2$ & 31.1 & 342.9 & 381.0 & 508.0 & 0.41 & 609.0 & $\mathrm{BK}$ \\
& $\mathrm{SP5}$ & 31.9 & 381.0 & 381.0 & 508.0 & 0.43 & 608.1 & $\mathrm{BK}$ \\
\hline \multirow{2}{*}{ Kanada vd. [9] } & $\mathrm{U} 20 \mathrm{~L}$ & 26.7 & 280.0 & 300.0 & 380.0 & 0.00 & 188.7 & $\mathrm{H}$ \\
& $\mathrm{U} 40 \mathrm{~L}$ & 24.3 & 280.0 & 300.0 & 380.0 & 0.00 & 266.2 & $\mathrm{~B}$ \\
\hline Sarsam ve Phipps [10] & $\mathrm{B} 101$ & 31.9 & 280.0 & 300.0 & 380.0 & 0.00 & 348.4 & $\mathrm{~B}$ \\
\hline Hoffschild vd. [11] & EX-2 & 52.5 & 154.5 & 272.0 & 305.0 & 0.13 & 176.3 & $\mathrm{BK}$ \\
\hline \multirow{2}{*}{ Ortiz [12] } & - & 26.3 & 177.5 & 190.0 & 200.7 & 0.10 & 148.7 & $\mathrm{~B}$ \\
\hline & BCJ1 & 34.0 & 200.0 & 300.0 & 400.0 & 0.00 & 306.0 & $\mathrm{~B}$ \\
& BCJ3 & 33.0 & 200.0 & 300.0 & 400.0 & 0.00 & 322.0 & $\mathrm{~B}$ \\
& BCJ5 & 38.0 & 200.0 & 300.0 & 400.0 & 0.08 & 314.0 & $\mathrm{~B}$ \\
& BCJ6 & 35.0 & 200.0 & 300.0 & 400.0 & 0.09 & 315.0 & $\mathrm{~B}$ \\
\hline
\end{tabular}


Tablo 1. Etriyesiz dış kiriş-kolon birleşim bölgesi veri tabanı (Devamı)

\begin{tabular}{|c|c|c|c|c|c|c|c|c|}
\hline Referans & Numune & $\begin{array}{c}f_{c} \\
(M P a)\end{array}$ & $\begin{array}{c}b_{j} \\
(\mathrm{~mm})\end{array}$ & $\begin{array}{c}h_{c} \\
(\mathrm{~mm})\end{array}$ & $\begin{array}{c}h_{b} \\
(\mathrm{~mm})\end{array}$ & $\frac{P}{f_{c} A_{g}}$ & $\begin{array}{c}V \\
(k N)\end{array}$ & $\begin{array}{c}\text { Hasar } \\
\text { Tipi }\end{array}$ \\
\hline \multirow{6}{*}{ Parker ve Bullman [13] } & $4 a$ & 39.0 & 275.0 & 300.0 & 500.0 & 0.00 & 198.6 & $\mathrm{CE}$ \\
\hline & $4 b$ & 39.0 & 275.0 & 300.0 & 500.0 & 0.09 & 232.3 & $\mathrm{~B}$ \\
\hline & $4 \mathrm{c}$ & 39.0 & 275.0 & 300.0 & 500.0 & 0.16 & 286.1 & B \\
\hline & $4 d$ & 39.0 & 275.0 & 300.0 & 500.0 & 0.00 & 252.4 & B \\
\hline & $4 \mathrm{e}$ & 39.0 & 275.0 & 300.0 & 500.0 & 0.09 & 269.3 & B \\
\hline & $4 \mathrm{f}$ & 39.0 & 275.0 & 300.0 & 500.0 & 0.17 & 308.0 & B \\
\hline \multirow{4}{*}{ Scott ve Hamil [14] } & C4ALN0 & 42.4 & 130.0 & 150.0 & 210.0 & 0.05 & 110.5 & KE \\
\hline & C4ALH0 & 104.0 & 130.0 & 150.0 & 210.0 & 0.02 & 188.2 & $\mathrm{KE}$ \\
\hline & C6LN0 & 51.0 & 130.0 & 150.0 & 210.0 & 0.04 & 104.1 & B \\
\hline & C6LH0 & 101.0 & 130.0 & 150.0 & 210.0 & 0.02 & 157.3 & B \\
\hline Wilson [15] & J1 & 32.0 & 154.0 & 300.0 & 300.0 & 0.30 & 261.9 & $\mathrm{~B}$ \\
\hline \multirow{6}{*}{ Clyde vd. [16] } & 01 & 33.1 & 406.4 & 406.4 & 406.4 & 0.15 & 859.4 & B \\
\hline & 02 & 33.1 & 406.4 & 406.4 & 406.4 & 0.03 & 798.8 & B \\
\hline & 03 & 34.0 & 406.4 & 406.4 & 406.4 & 0.10 & 815.9 & B \\
\hline & 04 & 34.0 & 406.4 & 406.4 & 406.4 & 0.25 & 901.9 & B \\
\hline & 05 & 31.7 & 406.4 & 406.4 & 406.4 & 0.10 & 857.0 & B \\
\hline & 06 & 31.7 & 406.4 & 406.4 & 406.4 & 0.25 & 862.8 & B \\
\hline \multirow{4}{*}{ Pantelides vd. [17] } & 02 & 46.2 & 304.8 & 457.2 & 406.4 & 0.10 & 951.7 & B \\
\hline & 04 & 37.0 & 304.8 & 457.2 & 406.4 & 0.25 & 929.4 & B \\
\hline & 05 & 40.1 & 304.8 & 457.2 & 406.4 & 0.25 & 982.5 & B \\
\hline & 06 & 41.0 & 304.8 & 457.2 & 406.4 & 0.10 & 940.5 & $\mathrm{~B}$ \\
\hline \multirow{2}{*}{ Ghobarah ve Said [18] } & $\mathrm{T}-1$ & 30.8 & 250.0 & 400.0 & 400.0 & 0.19 & 503.8 & BK \\
\hline & $\mathrm{T}-2$ & 30.8 & 250.0 & 400.0 & 400.0 & 0.10 & 503.8 & BK \\
\hline Gençoğlu ve Eren [19] & RCNH1 & 30.0 & 125.0 & 200.0 & 300.0 & 0.13 & 48.4 & KS \\
\hline El-Amoury ve Ghobarah [20] & T0 & 30.6 & 200.0 & 400.0 & 400.0 & 0.20 & 393.1 & BK \\
\hline \multirow{3}{*}{ Tsonos ve Stylianidis [21] } & L1 & 18.0 & 200.0 & 199.9 & 299.7 & 0.20 & 142.4 & $\mathrm{~B}$ \\
\hline & L2 & 18.0 & 200.0 & 199.9 & 299.7 & 0.20 & 163.1 & B \\
\hline & O1 & 18.0 & 200.0 & 199.9 & 299.7 & 0.20 & 142.4 & B \\
\hline Woo [22] & Model 5 & 26.5 & 167.0 & 167.0 & 200.0 & 0.00 & 72.1 & BK \\
\hline \multirow{3}{*}{$\begin{array}{l}\text { Antonopoulos ve Triantafillou } \\
\text { [23] }\end{array}$} & C-1 & 19.5 & 200.0 & 200.0 & 300.0 & 0.06 & 108.6 & B \\
\hline & $\mathrm{C}-2$ & 23.7 & 200.0 & 200.0 & 300.0 & 0.05 & 107.7 & B \\
\hline & $\mathrm{T}-\mathrm{C}$ & 24.6 & 200.0 & 200.0 & 300.0 & 0.05 & 124.9 & $\mathrm{~B}$ \\
\hline Hwang vd. [24] & 0T0 & 67.3 & 370.0 & 420.0 & 450.0 & 0.02 & 997.0 & BK \\
\hline \multirow{10}{*}{ Wong [25] } & BS-L & 30.9 & 280.0 & 300.0 & 450.0 & 0.15 & 315.5 & $\mathrm{~B}$ \\
\hline & BS-U & 31.0 & 280.0 & 300.0 & 450.0 & 0.15 & 341.2 & B \\
\hline & BS-L-LS & 31.6 & 280.0 & 300.0 & 450.0 & 0.15 & 344.9 & B \\
\hline & BS-L-300 & 34.1 & 280.0 & 300.0 & 300.0 & 0.15 & 505.0 & BK \\
\hline & BS-L-600 & 36.4 & 280.0 & 300.0 & 600.0 & 0.15 & 283.9 & B \\
\hline & BS-L-V2T10 & 32.6 & 280.0 & 300.0 & 450.0 & 0.15 & 398.8 & B \\
\hline & BS-L-V4T10 & 28.3 & 280.0 & 300.0 & 450.0 & 0.15 & 402.9 & $\mathrm{~B}$ \\
\hline & JA-NN03 & 44.8 & 280.0 & 300.0 & 400.0 & 0.03 & 304.2 & $\mathrm{BK}$ \\
\hline & JA-NN15 & 46.0 & 280.0 & 300.0 & 400.0 & 0.15 & 325.1 & BK \\
\hline & JB-NN03 & 47.4 & 280.0 & 300.0 & 300.0 & 0.03 & 317.0 & $\mathrm{BK}$ \\
\hline Liu [26] & RC-1 & 19.4 & 215.0 & 230.0 & 330.0 & 0.00 & 130.5 & BK \\
\hline Sağbaş [27] & ED1 & 31.1 & 342.9 & 381.0 & 508.0 & 0.00 & 596.4 & BK \\
\hline Salim [28] & $\mathrm{S} 1$ & 34.0 & 165.1 & 180.1 & 299.7 & 0.10 & 123.5 & $\mathrm{~B}$ \\
\hline \multirow{4}{*}{ Engindeniz vd. [29] } & SP1-NS & 25.8 & 330.5 & 356.0 & 508.0 & 0.02 & 362.2 & $\mathrm{CE}$ \\
\hline & SP1-EW & 25.8 & 330.5 & 356.0 & 508.0 & 0.02 & 401.9 & $\mathrm{CE}$ \\
\hline & SP2-NS & 34.6 & 330.5 & 356.0 & 508.0 & 0.02 & 408.0 & B \\
\hline & SP2-EW & 34.6 & 330.5 & 356.0 & 508.0 & 0.02 & 431.0 & $\mathrm{~B}$ \\
\hline \multirow{3}{*}{ Karayannis vd. [30] } & $\mathrm{A} 0$ & 31.6 & 200.0 & 200.0 & 300.0 & 0.05 & 81.2 & BK \\
\hline & B0 & 31.6 & 200.0 & 300.0 & 300.0 & 0.05 & 197.6 & $\mathrm{BK}$ \\
\hline & $\mathrm{CO}$ & 31.6 & 200.0 & 300.0 & 300.0 & 0.05 & 204.3 & $\mathrm{BK}$ \\
\hline \multirow{2}{*}{ Park [31] } & UJ2-EW & 27.3 & 431.8 & 457.2 & 762.0 & 0.20 & 748.3 & $\mathrm{~B}$ \\
\hline & UJ2-NS & 29.6 & 431.8 & 457.2 & 762.0 & 0.20 & 742.5 & B \\
\hline
\end{tabular}




\subsection{Birleşim Bölgesi Kesme Dayanımı Denklemleri}

Literatürde etriyesiz kiriş-kolon birleşim bölgelerinin kesme dayanımını tahmin etmek amacı ile çeşitli araştırmacılar tarafindan önerilmiş denklemler mevcuttur, ancak bu denklemlerden bir kısmı [10, 13, 24, 32, 33] daha önceki çalışmalarda karşılaştırma amacı ile kullanılımıştır [6, 34] ve deneylerden elde edilen kesme değerleri ile göz ardı edilemeyecek derecede uzak sonuçlar verdikleri istatistiksel ve grafiksel olarak gösterilmiştir. Mevcut çalışmada karşılaştırma amacıyla kullanılacak olan denklemler aşağıda yer almaktadır.

Hassan ve Moehle [34], $\kappa$ değerine bağlı olarak aşağıdaki denklemi önermiştir. $\kappa$, kolon eksenel basınç parametresidir.

$$
\begin{aligned}
& V_{n}=0.91 \sqrt{\frac{h_{c}}{h_{b}}} \kappa\left(\frac{b_{c}+b_{b}}{2}\right) h_{c} \sqrt{f_{c}^{\prime}} \\
& \kappa=1+\frac{4}{9}\left[\frac{P}{f_{c}^{\prime} A_{g}}-0.15\right] \\
& 1 \leq \kappa \leq 1.2
\end{aligned}
$$

Tsonos [35] temel gerilme-şekil değiştirme bağıntılarından faydalanarak Denklem 2'de yer alan eşitliği önermiştir.

$$
\left[\frac{h_{b} V_{n}}{2 b_{j} h_{c}^{2} f_{c}^{\prime}}\left(1+\sqrt{1+\frac{4}{\left(\frac{h_{b}}{h_{c}}\right)^{2}}}\right)\right]^{5}+\frac{5 h_{b} V_{n}}{b_{j} h_{c}^{2} f_{c}^{\prime}}\left(\sqrt{1+\frac{4}{\left(\frac{h_{b}}{h_{c}}\right)^{2}}}-1\right)=1
$$

Vollum ve Newman [36] kafes-kiriş yöntemini kullanarak etriyeli ve etriyesiz birleşim noktalarının kesme dayanımlarını belirleyebilmek amacı ile aşağıdaki denklemi (Denklem 3) önermişlerdir. Burada $\zeta$ birleşim bölgesindeki donatının bükülme şeklini hesaba katan bir katsayıdır ve Tablo 1 'de yer alan elemanlar için $\zeta=1$ alınmıştır.

$$
V_{n}=0.642 \zeta\left[1+0.555\left(2-h_{b} / h_{c}\right)\right]\left(\frac{b_{c}+b_{b}}{2}\right) h_{c} \sqrt{f_{c}^{\prime}}
$$

\section{3. Önerilen Etriyesiz Dış Kiriş-Kolon Birleşim Bölgesi Kesme Dayanımı Hesap Denklemi}

Yapılan çalışma kapsamında, etriyesiz dış kiriş-kolon birleşim bölgesinde açığa çıkacak olan kesme dayanımı üzerinde etkili olan en önemli parametreler: efektif birleşim bölgesi genişliği, beton basınç dayanımı, kiriş efektif alanının kolon efektif alanına oranı ve eksenel yük oranı olarak belirlenmiştir.

Birleşim bölgesinde etkili olacak beton basınç alanının belirlenebilmesi için efektif birleşim bölgesi genişliğinin $\left(b_{j}\right)$ gerçekçi şekilde hesaplanması gereklidir. Bu parametrenin hesabı için yönetmelikler ve araştırmacılar farklı hesap yöntemleri önermektedir. 1997 Türkiye Deprem Yönetmeliği [37]'nde Şekil 2'de verilen deprem doğrultusu ve eleman boyutlarına bağlı olarak $b_{j}$ 'nin hesabı için Denklem 4 önerilmiştir. Bu denklemde birleşim bölgesinde deprem yönüne paralel olan kirişlerden genişliği $\left(b_{w 1}, b_{w 2}\right)$ küçük olanı esas alınarak hesaplama yapılmaktadır. $b_{1}$ ve $b_{2}$, genişliği küçük olan kirişin düşey ekseninin kolon kenarlarına olan uzaklı̆̆ıdır. Efektif birleşim bölgesi genişliği bu iki uzaklıktan küçük olanın iki katı olarak alınmıştır. Ancak bu değerin dikkate alınan kiriş genişliği ile kolon genişliğinin $(h)$ toplamından küçük ve/veya eşit olması zorunluluğu vardır.

$$
b_{w 1}<b_{w 2} \text { için } b_{j}=2 \min \left(b_{1} ; b_{2}\right) ; b_{j} \leq\left(b_{w 1}+h\right)
$$


2007 ve 2019 Türkiye Deprem Yönetmeliklerinde [38, 5] Denklem 4'e ek bir durum dikkate alınmıştır. Eğer deprem doğrultusundaki kirişlerin her ikisinin genişliği de kolonun aynı doğrultudaki genişliğinden $(b)$ büyük ve/veya eşit ise efektif birleşim bölgesi genişliği için doğrudan kolonun genişliğinin alınması durumu eklenmiştir (Denklem 5).

$$
\left.\begin{array}{l}
b_{w 1} \text { ve } b_{w 2} \geq b \text { için } b_{j}=b \\
b_{w 1} \text { ve } b_{w 2}<b \text { için } b_{j}=2 \min \left(b_{1} ; b_{2}\right) \\
b_{w 1}<b_{w 2} \text { için } b_{j} \leq\left(b_{w 1}+h\right)
\end{array}\right\}
$$

ACI-352 [39]'de ise Denklem 6'da yer alan denklemlerden elde edilen en küçük sonucun kullanılması önerilmektedir. Burada $m$ sabit bir değerdir ve kiriş ekseni ile kolonun ağırlık merkezi arasındaki sapmanın kolon genişliğinin sekizde birini $\left(b_{c} / 8\right)$ aşması durumunda $m=0.3$, diğer tüm durumlarda ise $m=0.5$ alınmaktadır. Dikkat edilmesi gereken nokta, ikinci denklemde, deprem doğrultusunda kolona birleşen tüm kirişlerin hesaba katılması gerekliliğidir.

$$
b_{w 1} \leq b_{w 2} \text { için }\left\{\begin{array}{l}
b_{j}=\frac{b_{w 1}+b}{2} \\
b_{j}=b_{w 1}+\sum \frac{m \times h}{2} \\
b_{j}=b
\end{array}\right.
$$

Zhang ve Jirsa [40] kiriş-kolon birleşim bölgesi deneyleri sonucunda, birleşim bölgesinde oluşan basınç bölgesinin kolon ve kiriş genişliklerinden ziyade iki değerin ortasında bir değere sahip olduğunu belirtmişler ve aşağıdaki denklemi önermişlerdir (Denklem 7). Bu denklem ACI-352 [39]'de de kullanılmaktadır (Denklem 6). Mevcut çalışmada da $b_{j}$ değerleri Denklem 7 kullanılarak hesaplanmıştır.

$$
b_{j}=\frac{b_{w \min }+b}{2}
$$

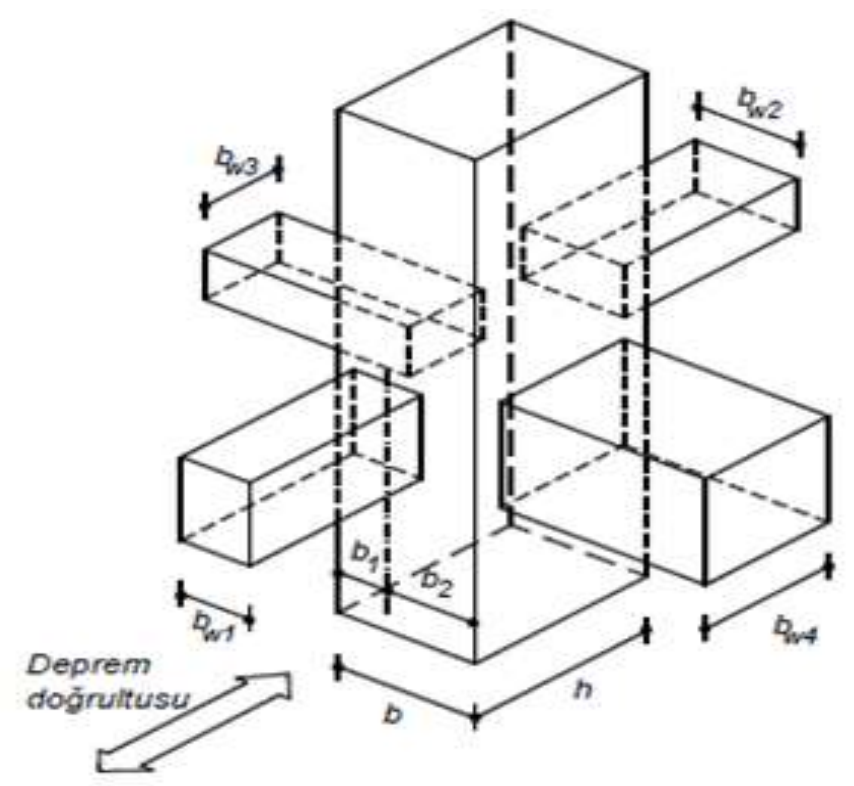

Şekil 2. Türkiye Deprem Yönetmeliği kuşatılmış birleşim bölgesi gösterimi [39] 
Eksenel yükün, kiriş-kolon birleşim bölgesinin kesme dayanımı üzerindeki etkisi literatürde yer alan pek çok çalışmanın konusu olmuştur. Bazı çalışmalar [16, 17, 41] eksenel yükün artması ile birlikte birleşim bölgesi kesme dayanımının arttığını öne sürerken, tam tersini savunan [42] veya herhangi bir değişime sebep olmadığ doğrultusunda görüşler bildiren çalışmalar da mevcuttur [43]. Bu tip farklı sonuçların ortaya çıkması, birleşim bölgesinde yer alan elemanların durumlarına göre değişebilmekte ve oluşabilecek farklı kesme dayanımı mekanizmalarından ileri gelebilmektedir. Zayıf kolon-güçlü kiriş durumunda kolon eksenel yükünün dengeli duruma kadar artırılması ile birleşim bölgesinin kesme dayanımı artabilirken güçlü kolon-zayıf kiriş durumlarında eksenel yükün artmasının bu durum üzerinde hem pozitif hem de negatif etkileri görülebilir [6]. Tablo 1'de yer alan elemanların eksenel yük oranının kesme kuvvetine etkisini yansıtan dağılım Şekil 3'te verildiği gibidir. Söz konusu dağılıma bakıldığında, mevcut datalar için kolon eksenel yük oranının 0.25 'ten büyük olduğu durumlarda birleşim bölgesinin kesme dayanımı üzerindeki etkisi daha net görülmektedir, ancak böyle bir sınırlama getirebilmek için daha fazla deney verisi gerekmektedir. Bu sınır farklı çalışmalarda 0.2 olarak verilmişsir [6, 34]. Burada $P$ : eksenel kuvvet, $f_{c}$ : silindir beton basınç dayanımı, $A_{g}$ ise kolon en kesit alanıdır $\left(h_{c} \times b_{c}\right)$.

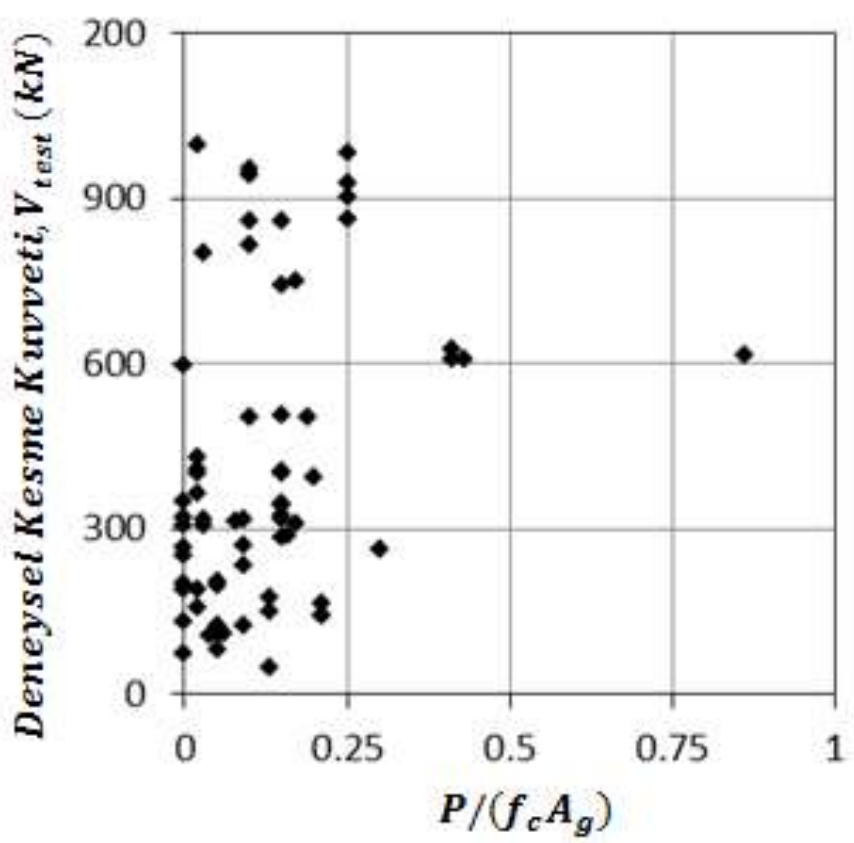

Şekil 3. Eksenel yük oranının kesme kuvvetine etkisi

Etriyesiz kiriş-kolon birleşim bölgesinin kesme dayanımını tahmin etmek için öncelikle efektif birleşim bölgesinin katkısı dikkate alınmıştır (Denklem 8). Bu kullanım Denklem 1 ve Denklem 3 'te de aynı şekilde kullanılmıştır.

$$
V_{\text {model }}=b_{j} \sqrt{f_{c}} h_{c}
$$

Çalışma kapsamında dikkate alınan numunelere bakıldığında göz önüne alınan deprem doğrultusundaki kiriş ve kolon efektif en kesit alanlarının oranının $\left(h_{b} / h_{c}\right)$ artması ile birleşim bölgesi kesme dayanımının azaldığı görülmüştür (Şekil 4). Bu sebeple Şekil 4'teki dağılımdan yola çıkılarak $h_{b} / h_{c}$ 'ye bağlı olarak aşağıdaki denklem elde edilmiştir (Denklem 9).

$$
V_{\text {model }} /\left(b_{j} \sqrt{f_{c}} h_{c}\right)=0.8668\left(h_{b} / h_{c}\right)^{-0.737}
$$




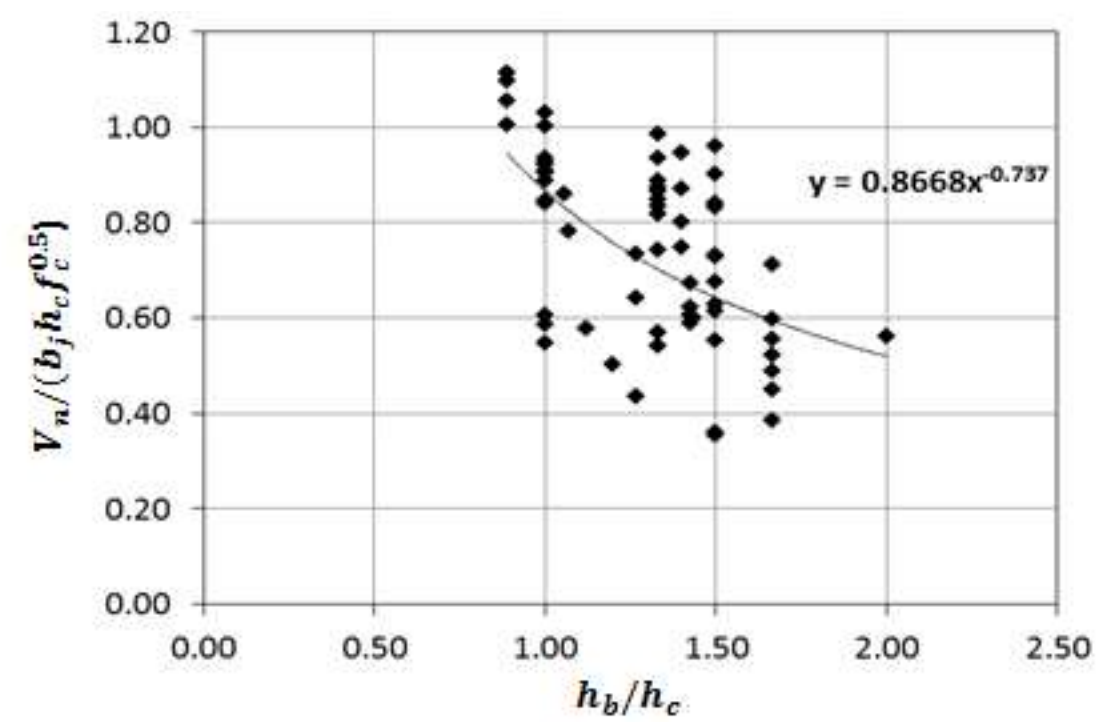

Şekil 4. Kiriş efektif alanının kolon efektif alanına oranın birleşim bölgesi kesme dayanımı üzerindeki etkisi

Kullanım kolaylığı açısından 0.8668 değeri yerine $0.87 ; 0.737$ değeri yerine ise 0.74 kullanılmıştır ve Denklem 8 aşağıdaki formu almıştır (Denklem 10).

$$
V_{\text {model }}=b_{j} \sqrt{f_{c}} h_{c} \times 0.87\left(\frac{h_{c}}{h_{b}}\right)^{0.74}
$$

Birleşim bölgesi kesme dayanımı üzerinde etkili olduğu kabul edilen bir diğer parametre de eksenel yük oranı $\left(\frac{P}{f_{c} A_{g}}\right)$ olarak belirlenmiştir. Denklem 10'a bağlı olarak hesaplanan kesme dayanımlarının Tablo 1'de de yer alan eksenel yük oranlarına bağlı değişimini veren dağılım Şekil 5'te verildiği gibidir. Dağılımdan elde edilen denkleme bağlı olarak Denklem 10'un eksenel yük oranına göre değişimini yansıtan denklem Denklem 11'de verilmiştir.

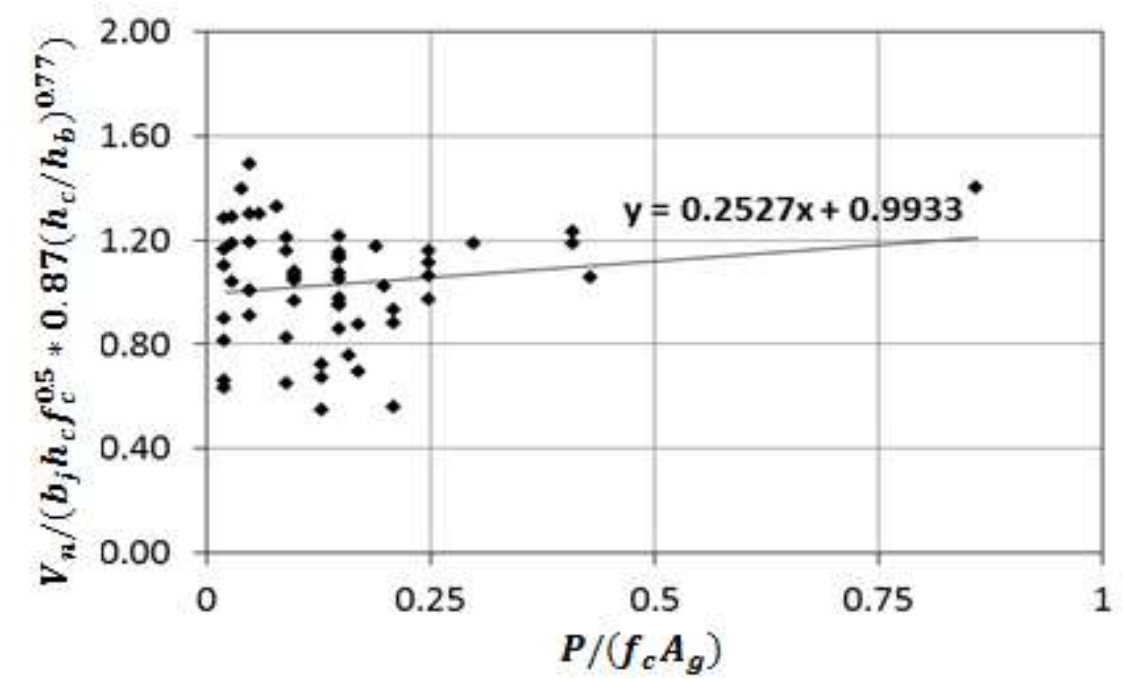

Şekil 5. Eksenel yük oranının birleşim bölgesi kesme dayanımı üzerindeki etkisi

$$
V_{\text {model }} /\left(b_{j} \sqrt{f_{c}} h_{c} \times 0.87\left(\frac{h_{c}}{h_{b}}\right)^{0.74}\right)=0.2527 \frac{P}{f_{c} A_{g}}+0.9923
$$


Denklem 11 'de yer alan 0.2527 değeri yerine $0.25 ; 0.9923$ yerine ise 1.0 kullanılarak elde edilen ve mevcut çalışma kapsamında etriyesiz dış kiriş-kolon birleşim bölgesi kesme dayanımı hesabı için kullanımı öngörülen denklemin son hali Denklem 12'de verildiği gibidir:

$$
V_{\text {model }}=b_{j} \sqrt{f_{c}} h_{c} \times 0.87\left(\frac{h_{c}}{h_{b}}\right)^{0.74} \times\left(0.25 \frac{P}{f_{c} A_{g}}+1.0\right)
$$

\section{Bulgular ve Tartışma}

\subsection{Sonuçların Karşılaştırılması}

Çalışma kapsamında, etriyesiz dış kiriş-kolon birleşim bölgelerinin kesme dayanımını hesaplayabilmek için Denklem 12 önerilmiştir. Önerilen denklemin (Denklem 12) kullanılabilirlik durumunu belirleyebilmek amacı ile deney sonuçları ve literatürden derlenen denklemlerin karşılaştırılması yapılmıştır. Karşılaştırmalar yapılırken yüzdesel ortalama mutlak hata (ORT. M. H. (\%)) (Denklem 13), ortalama (ORT.) (Denklem 14), $V_{\text {model }} / V_{\text {test }}$ için dağılımlardan elde edilen mimimum (MİN.) ve maksimum (MAKS.) değerler kullanılmıştır.

$$
\begin{aligned}
& \text { ORT. M. H. }(\%)=\left|\frac{\sum_{i=1}^{n}\left(V_{\text {test }}-V_{\text {model }}\right)}{V_{\text {test }}}\right| \times 100 \\
& \text { ORT. }=\frac{1}{n} \sum_{i=1}^{n} \frac{V_{\text {test }}}{V_{\text {model }}}
\end{aligned}
$$

Burada $V_{\text {test }}$ ve $V_{\text {model }}$ sirasiyla deneysel ve hesaplanan kesme dayanımlarıdır. $n$ ise veritabanında yer alan numune sayısını göstermektedir.

Tablo 2. Hesaplardan elde edilen sonuçlar

\begin{tabular}{lrccc}
\hline \multicolumn{1}{c}{ Denklem } & $\begin{array}{l}\text { ORT. M. H. } \\
(\%)\end{array}$ & ORT. & MIN. & MAKS. \\
& 37.66 & 0.77 & 0.40 & 1.08 \\
\hline Hassan ve Moehle [34] & 40.36 & 0.85 & 0.40 & 2.44 \\
Tsonos [35] & 27.98 & 0.84 & 0.43 & 1.17 \\
Vollum ve Newman [36] & 18.00 & 1.00 & 0.53 & 1.42 \\
Önerilen Denklem & &
\end{tabular}

Söz konusu elemanlar (Tablo 1) için yapılan karşılaştırmalardan elde edilen sayısal değerler Tablo 2'de, dağılımlar ise Şekil 6'da verilmiştir. Tablo 2'deki MAKS. değerlerine bakıldığında Tsonos [35]'un önermiş olduğu denklemin (Denklem 2) sonucu 2.44 ile diğer tüm değerlerden büyük çıkmıştır. Ancak MAKS. ve MiN. değerleri sadece birer noktayı işaret ettiği için diğer değerlere de bakmak gerekliliği vardır. Söz konusu denklemin (Denklem 2) ORT. M. H. (\%) değeri de (40.36) MAKS. değerinde olduğu gibi diğer denklemlere göre oldukça yüksek bir değere sahiptir. Hassan ve Moehle [34]'nin önermiş olduğu denklemin (Denklem 1) 37.66'lık ORT. M. H. (\%) ve 1.08'lik MAKS. değerleri ile her ne kadar Tsonos [35]'un sonuçlarına göre deney sonuçlarına daha yakın sonuçlar vermiş olsa da 0.77'lik ORT. değeri ile deney sonuçlarına yeterince yaklaşmadığı görülmektedir. Şekil 6'daki (2) numaralı grafik de Hassan ve Moehle [34]'nin deney sonuçlarının büyük çoğunluğunu küçük tahmin ettiğini göstermektedir. Vollum ve Nevman [36]'ın denklemi (Denklem 3) ile önerilen denklemin (Denklem 12) MAKS. sonuçları karşılaştıııldığında 1.17 ile Vollum ve Nevman [36]'ın sonucu 1.42 olan önerilen denklemin sonucuna göre çok daha kabul edilebilir görünmektedir, ancak bu değerin tek bir noktayı işaret etmesinden dolayı diğer sonuçların da karşılaştırılması gerekmektedir. Bu iki denklem için (Denklem 3, 12) ORT. M. H. (\%) $(27.98,18.00)$, ORT. $(0.84,1.00)$ ve MİN. $(0.43,0.53)$ değerleri karşılaştırıldığında önerilen denklemin (Denklem 12) diğer denklemden (Denklem 2) daha iyi sonuç verdiği anlaşılmaktadır. Tablo 2'deki sonuçlar ve Şekil 6'daki dağılımlar karşılaştırıldığında önerilen 
denklemin (Denklem 12) dikkate alınan diğer denklemlere göre deney sonuçlarını daha iyi tahmin ettiği görülmektedirn.

Şekil 7'de ise sonuçların hasar durumlarına göre dağılımları verilmiştir. Grafiklerden görüleceği gibi, özellikle en sık rastlanan hasar durumu olan birleşim bölgesinde kiriş donatısında akma meydana gelmeden açığa çıkan kesme hasarı (B) için önerilen denklem (Denklem 12) deney sonuçları ile en yakın sonuçları vermektedir. $\mathrm{Bu}$ durumun diğer hasar durumları için de geçerli olduğu grafiklerden anlaşılabilmektedir.
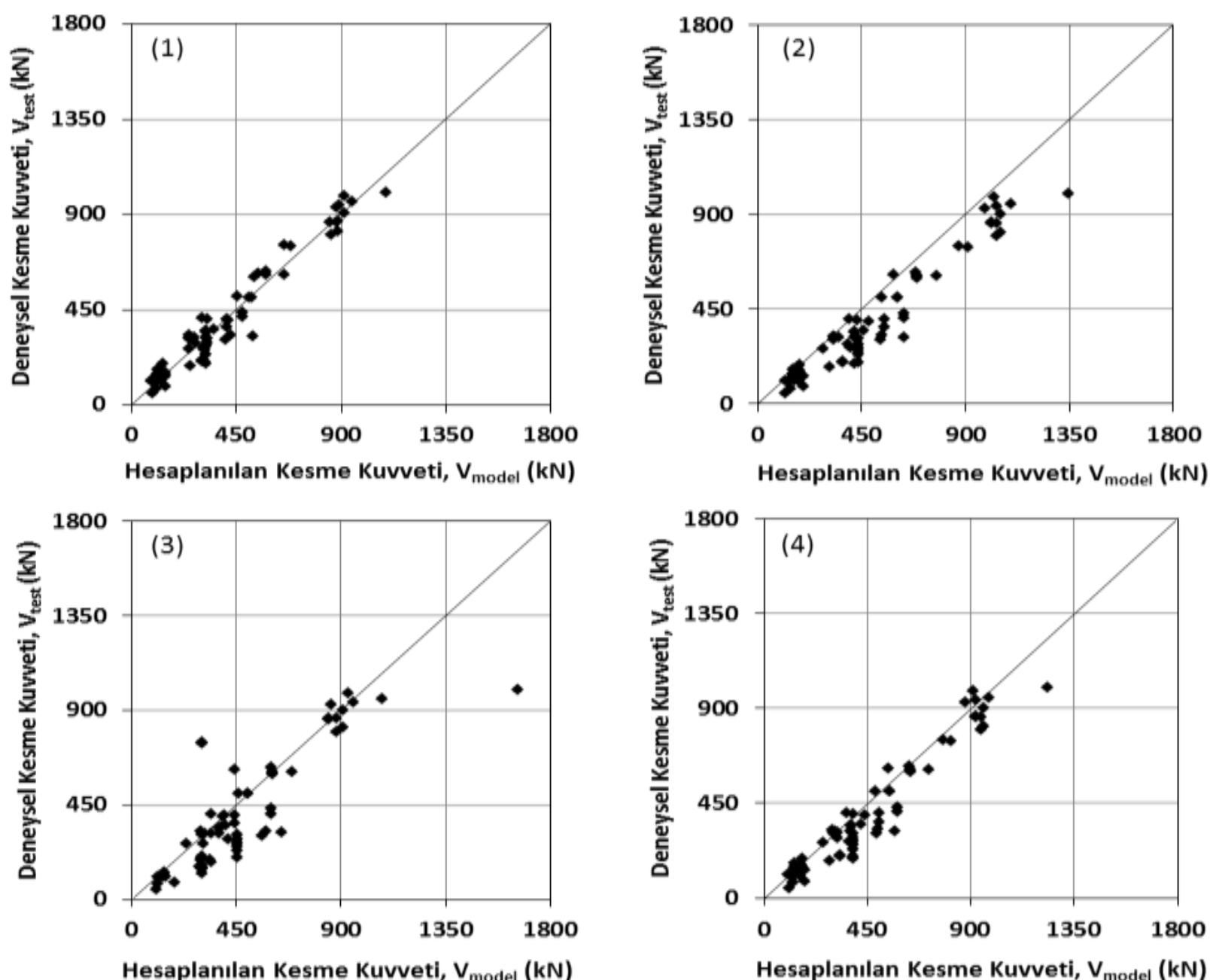

Şekil 6. Hesaplanan kesme kuvvetleri ile deneysel kesme kuvvetlerinin karşılaştırması 1) Önerilen Denklem (12); 2)Hassan ve Moehle (Denklem 1); 3) Tsonos (Denklem 2); 4) Vollum ve Newman (Denklem 3) 

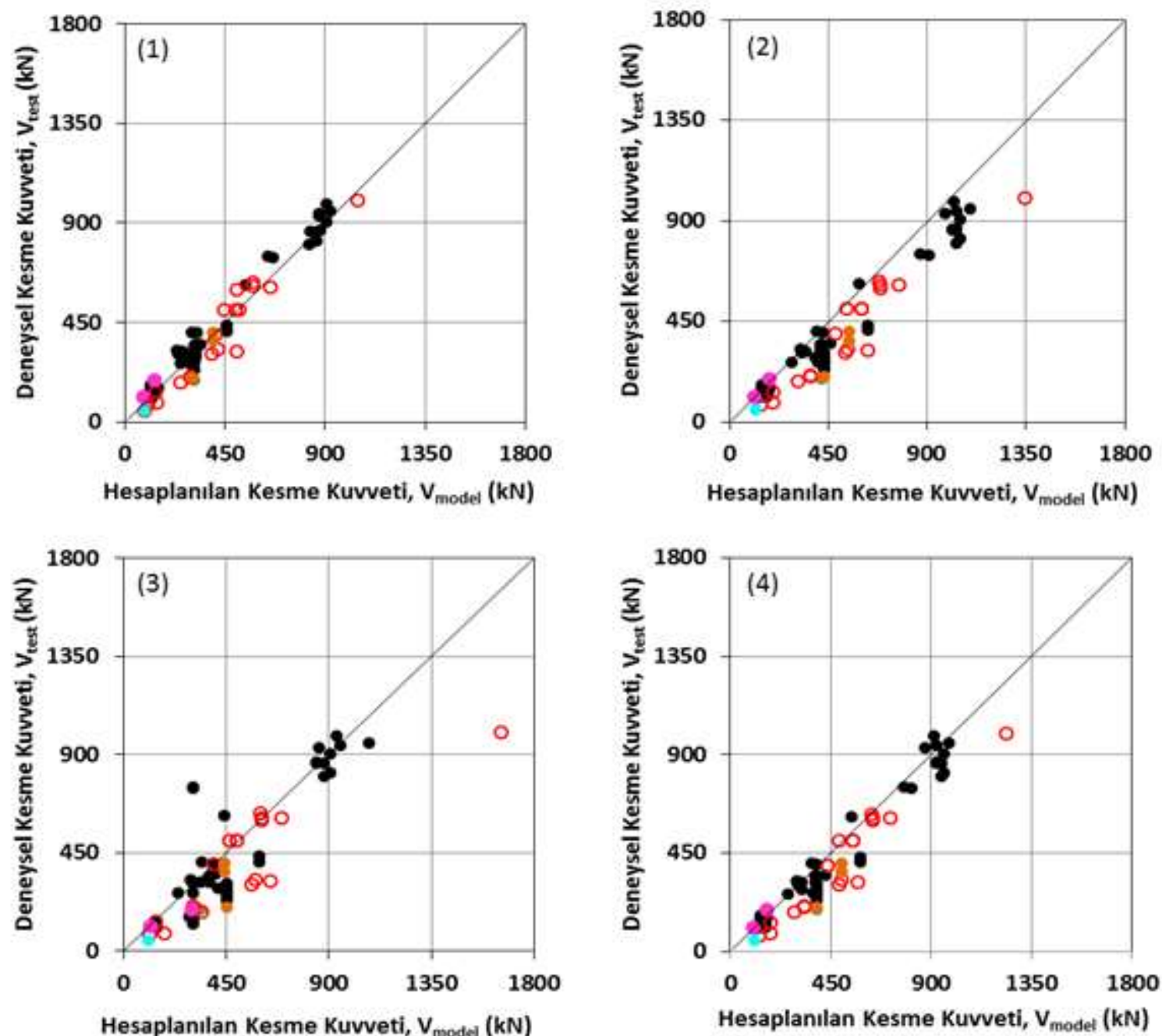

Hesaplanilan Kesme Kuvveti, $\mathrm{V}_{\text {model }}(\mathrm{kN})$

Hesaplanilan Kesme Kuvveti, $\mathrm{V}_{\text {model }}(\mathrm{kN})$

- $\bullet B$ BK $\bullet$ KE $\odot$ CE KS

Şekil 7. Sonuçların hasar biçinlerine göre karşılaştırılması 1) Önerilen Denklem (12); 2)Hassan ve Moehle (Denklem 1); 3) Tsonos (Denklem 2); 4) Vollum ve Newman (Denklem 3)

\section{Sonuçlar}

Bu çalışmada, literatürde yer alan 25 farklı çalışmadan 68 adet etriyesiz dış kiriş-kolon birleşim bölgesi verisi derlenmiş ve bu verilere dayanılarak etriyesiz dış kiriş-kolon birleşim bölgesinin kesme dayanımına etki eden parametreler: efektif birleşim bölgesi genişliği, beton basınç dayanımı, kiriş efektif alanının kolon efektif alanına oranı ve eksenel yük oranı olarak belirlenmiştir. Söz konusu parametrelere bağlı olarak yeni bir kesme dayanımı denklemi önerilmiştir ve literatürdeki denklemlerle karşılaştırılmıştır. Çalışma sonunda elde edilen bulgular:

1) Kolon eksenel yük oranının 0.25 'i geçmesi durumunda eksenel yükün birleşim bölgesinin kesme dayanımı üzerinde daha etkili olduğu görülmüştür, ancak bu durumun daha fazla deney sonucu ile doğrulanması gerekmektedir.

2) Efektif kolon enkesit alanının efektif kiriş enkesit alanına oranı birleşim bölgesi kesme dayanımını artırmaktadır.

3) Önerilen denklem herhangi bir malzeme dayanımı, kesit boyutu ve yük sınırı içermediğinden dikkate alınan özellikteki birleşim bölgelerinde kullanıma uygundur. Önerilen denklem literatürde yer alan üç farklı denklemle karşılaştırılmış ve sonuçlar sayısal (Tablo 2) ve grafiksel (Şekil 6) olarak verilmiştir. Denklem sonuçları yüzdesel ortalama mutlak hata (ORT. M. H. (\%), Denklem 13), ortalama (ORT., Denklem 14), MiN. ve MAKS. değerleri açısından 
karşılaştırılmıştır. Önerilen denklemin ORT. M. H. (\%) değeri 18.00 ile diğer sonuçlardan daha küçüktür $(37.66,40.36,27.98)$. Ayrıca önerilen denklemin 1.00 olarak elde edilen ORT. değeri ile deney sonuçlarına diğer denklem sonuçlarından $(0.77,0.85,0.84)$ daha çok yakınsadığı görülmüştür.

4) Tablo 1'de verilen datalar için gözlenen hasar durumları arasında en sık rastlanan hasar durumunun (B) birleşim bölgesinde kiriş donatısında akma meydana gelmeden açığa çıkan kesme hasarı olduğu görülmektedir. Bu sebeple akma gerilmesine doğrudan bağlı bir denklem önerilmemiştir. Yine Şekil 7'den de görüleceği gibi önerilen formül, birleşim bölgesinde kiriş boyuna donatısının akması neticesinde oluşan hasar durumu (BK) dahil tüm hasar durumları için diğer formüllerle karşılaştıııldığında deney sonuçlarına en yakın sonuçları vermektedir.

\section{Yazarların Katkısı}

Makalede tüm katkı şahsıma aittir.

\section{Çıkar Çatışması Beyanı}

Yazarlar arasında herhangi bir çıkar çatışması bulunmamaktadır.

\section{Araştırma ve Yayın Etiği Beyanı}

Yapılan çalışmada araştırma ve yayın etiğine uyulmuştur.

\section{Kaynaklar}

[1] Işık E., Özdemir M. 2016. Betonarme Yapılarda Güçlü Kiriş-Zayıf Kolon Durumunun Yap1 Performansına Etkisi, 1st International Mediterranean Science and Engineering Congress (IMSEC), pp 1-10, 26-28 Ekim, Adana.

[2] Eyyubov C., Şahin A., Uğur Y. 2005. Yıkıcı Depremler Süresince Betonarme Binaların KolonKiriş Birleşimlerinin Davranışlarının İncelenmesi, Antalya Yöresinin İnşaat Mühendisliği Sorunları Kongresi, İmo İnşaat Mühendisleri Odası, e-kütüphane.

[3] Yönetmelik, Afet Bölgelerinde Yapılacak Yapılar Hakkında. 1968. İmar ve İskan Bakanlığ1, Deprem Araştırma Dairesi, 17s, Ankara.

[4] Yönetmelik, Afet Bölgelerinde Yapılacak Yapılar Hakkında. 1975. İmar ve İskan Bakanlığ1, Deprem Araştırma Dairesi, 37s, Ankara.

[5] Türkiye Bina Deprem Yönetmeliği. 2019. Afet ve Acil Durum Yönetimi Başkanlığı, 395s, Ankara.

[6] Park S., Mosalam K.M. 2012. Parameters for Shear Strength Prediction of Exterior Beam-Column Joints without Transverse Reinforcement, Engineering Structures, 36 (2012): 198-209.

[7] Hanson N.W., Conner H.W. 1967. Seismic Resistance of Reinforced Concrete Beam-Column Joints, Journal of Structural Division, Journal of the Structural Division, 93 (5): 533-560.

[8] Uzumeri S.M. 1977. Strength and Ductility of Cast-in-Place Beam-Column Joints. American Concrete Institute Annual Convention, Symposium on Reinforced Concrete Structures in Seismic Zones, pp 293-350, San Francisco.

[9] Kanada K., Kondo G., Fujii S., Morita S. 1984. Relation Between Beam Bar Anchorage and Shear Resistance at Exterior Beam-Column Joints, Transaction of the Japan Concrete Institute, 6: 433440.

[10] Sarsam K.F., Phipps M.E. 1985. The Shear Design of in Situ Reinforced Ream-Column Joints Subjected to Monotonic Loading, Magazine of Concrete Reasearch, 37 (130): 16-28.

[11] Hoffschild T.E., Prion H.G.L., Cherry S. 1995. Seismic Retrofit of Beam-to-Column Joints with Grouted Steel Tubes, Proceedings, Tom Paulay Symposium on Recent Development in Lateral Force Transfer in Buildings, pp 397-425, Detroit, Michigan.

[12] Reys De Otiz I. 1993. Strut-and-Tie Modeling of Reinforce Concrete Short Beams and BeamColumn Joints, University of Westminster, PhD thesis, Department of Civil Engineering, London, UK. 
[13] Parker D.E., Bullman P.J.M. 1997. Shear Strength within Reinforced Concrete Beam-Column Joints, Structural Engineer, 75 (4): 53-57.

[14] Scott R.H., Hamill S.J. 1998. Connection Zone Strain in Reinforced Concrete Beam Column Connection, In: Proceedings of the 11th International Conference on Experimental Mechanics, pp 65-69, 1-4 February, Oxford.

[15] Wilson I.D. 1998. SIFCON Joints in Pre-cast Concrete Structures, In: Proceedings of the 8th BCA Annual Conference on Higher Education and the Concrete Industry, pp 227-239, July, Southampton.

[16] Clyde C., Pantelides C.P., Reaveley L.D. 2000. Performance-Based Evaluation of Exterior Reinforced Concrete Building Joints for Seismic Excitation, PEER Report 2000/05, Berkeley: Pacific Earthquake Engineering Research Center, University of California.

[17] Pantelides C.P., Hansen J., Nadauld J., Reaveley L.D. 2002. Assessment of Reinforced Concrete Building Exterior Joints with Substandard Details, PEER Report 2002/18, Berkeley: Pacific Earthquake Engineering Research Center, University of California.

[18] Ghobarah A., Said A. 2002. Shear Strengthening of Beam-Column Joints, Engineering Structures, 24 (7): 881-888.

[19] Gencoğlu M., Eren I. 2002. An Experimental Study on the Effect of Steel Fiber Reinforced Concrete on the Behavior of the Exterior Beam-Column Joints Subjected to Reversal Cyclic Loading, Turkish Journal of Engineering and Environmental Sciences, 26 (6): 493-502.

[20] El-Amoury T., Ghobarah A. 2002. Seismic Rehabilitation of Beam-Column Joints Using GFRP Sheets, Engineering Structures, 24 (11): 1397-1407.

[21] Tsonos A.G., Stylianidis K. 2002. Seismic Retrofit of Beam-to-Column Joints with High-Strength Fiber Jackets, European Earthquake Engineering, 16 (2): 56-72.

[22] Woo S.W. 2003. Seismic Performance of RC Frames in a Low to Moderate Seismicity Region, $\mathrm{PhD}$ thesis, Korea University, Department of Civil Engineering, Seoul, Korea.

[23] Antonopoulos C.P., Triantafillou T.C. 2003. Experimental Investigation of FRP-Strengthened RC Beam-Column Joints, Journal of Composites for Construction, 7 (1): 39-49.

[24] Hwang S.J., Hung-Jen L., Liao T.F., Kuo-Chou Wang., Tsai H.H. 2005. Role of Hoops on Shear Strength of Reinforced Concrete Beam-Column Joints, ACI Structural Journal, 102 (3): 445-453.

[25] Wong H.F. 2005. Shear Strength and Seismic Performance of Non-Seismically Designed Reinforced Concrete Beam-Column Joints, $\mathrm{PhD}$ thesis, The Hong Kong University of Science and Technology, Department of Civil Engineering, Clear Water Bay, Hong Kong.

[26] Liu C. 2006. Seismic Behavior of Beam-Column Joint Assemblies Reinforced with Steel Fibers, MSc thesis, University of Canterbury, Department of Civil Engineering, Christchurch, Canterbury, New Zealand.

[27] Sagbas G. 2007. Nonlinear Finite Element Analysis of Beam-Column Subassemblies, MSc thesis, University of Toronto, Department of Civil Engineering, Toronto, Kanada.

[28] Salim I.B. 2007. The Influence of Concrete Strengths of the Behavior of the External BeamColumn Joints, PhD thesis, Universiti Teknologi Malaysia, Johor Bahru, Malaysia.

[29] Engindeniz M., Kahn L.F., Zureick A.H. 2008. Performance of an RC Corner Beam-Column Joint Severely Damaged under Bidirectional Loading and Rehabilitated with FRP Composites, Seismic Strengthening of Concrete Building Using FRP Composites, 25.

[30] Karayannis C.G., Chalioris C.E., Sirkelis G.M. 2008. Local Retrofit of Exterior RC BeamColumn Joints Using Thin RC Jackets-An Experimental Study, Earthquake Engineering \& Structural Dynamics, 37 (5): 727-746.

[31] Park S. 2010. Experiential and Analytical Studies on Old Reinforced Concrete Buildings with Seismically Vulnerable Beam-Column Joints, PhD thesis, UC Berkeley, Berkeley, America.

[32] Bakir P.G., Boduroğlu H.M. 2002. A New Design Equation for Predicting the Joint Shear Strength of Monotonically Loaded Exterior Beam-Column Joints, Engineering Structures, 24 (8): 1105-1117.

[33] Hegger J., Sherif A., Roeser W. 2003. Nonseismic Design of Beam-Column Joints, Structural Journal, 100 (5): 654-664.

[34] Hassan W.M., Moehle J.P. 2018. Shear Strength of Exterior and Corner Beam-Column Joints without Transverse Reinforcement, ACI Structural Journal, 115 (6): 1719-1727. 
[35] Tsonos A.D.G. 2010. Performance Enhancement of R/C Building Columns and Beam-Columns Joints through Shotcrete Jacketing, Engineering Structures, 32 (3): 726-740.

[36] Vollum R.L., Newman J.B. 1999. Strut and Tie Models for Analysis/Design of External BeamColumn Joints, Magazine of Concrete Research, 51 (6): 415-425.

[37] Yönetmelik, Afet Bölgelerinde Yapılacak Yapılar Hakkında. 1997. Bayındırlık ve İskan Bakanlığı, 86s, Ankara.

[38] Yönetmelik, Deprem Bölgelerinde Yapılacak Binalar Hakkında. 2007. Afet İşleri Genel Müdürlüğü, Deprem Araştırma Dairesi, 156s, Ankara.

[39] Recommendations for Design of Beam-Column Connections in Monolithic Reinforced Concrete Structures, 2002. ACI-ASCE Committee 352, American Concrete Institute, 37s. Farmington Hills.

[40] Zhang L., Jirsa J.O. 1982. A Study of Shear Behavior of Reinforced Concrete Beam-Column Joints, PMFSEL Report No. 82-1, University of Texas at Austin.

[41] Barnes M., Jigoral S. 2008. Exterior Non-Ductile Beam Column Joints PEER/NEESREU Research Report, University of California, Berkeley.

[42] Vecchio F.J., Collins M.P. The Modified Compression-Field Theory for Reinforced Concrete Elements Subjected to Shear, ACI Structural Journal, 83 (2): 219-231.

[43] Pantazopoulou S., Bonacci J. 1993. Consideration of Questions about Beam-Column Joints, Structural Journal, 89 (1): 27-36. 